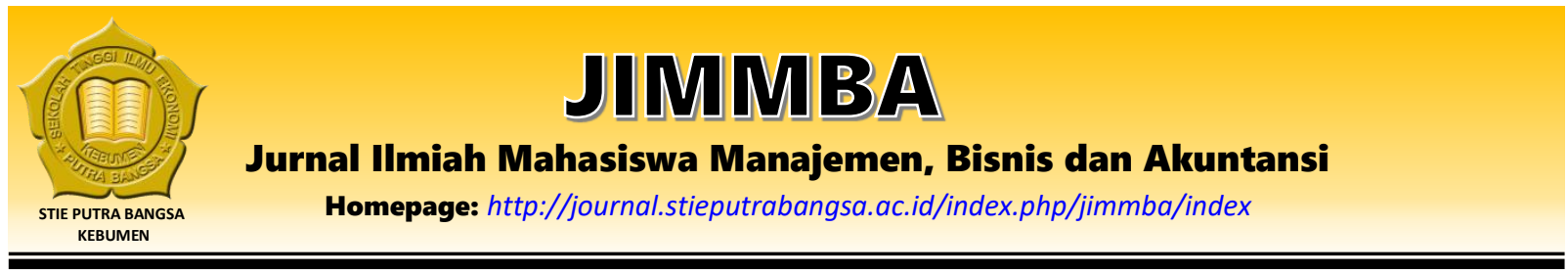

\title{
Pengaruh Corporate Governance dan Women on Board Terhadap Kinerja Perusahaan Sub Sektor Kosmetik Terdaftar di BEI Tahun 2015-2019
}

\author{
Mayang Sari Saragi ${ }^{1}$, Valentine Siagian ${ }^{2}$ \\ 1, 2 Universitas Advent Indonesia \\ Email: 1833008@unai.edu ${ }^{1}$
}

ARTICLE INFO

Article History:

Received: April 9th 2021

Accepted: April 26 2021

Published: May $5^{\text {th }} 2021$

Keywords:

Corporate Governance,

Women on Board, Firm

Performance

\begin{abstract}
In this study, the author aims to see the influence between Corporate Governance and Women on Board on the Financial Performance of the Cosmetics sub-sector companies listed on the Indonesia Stock Exchange in 2015-2019. The data used in this study are secondary data taken from the financial statements of cosmetic companies listed on the Indonesia Stock Exchange with the research sample of 30 cosmetic companies. In this study, corporate governance with an indicator of the proportion of independent commissioners and women on board with an indicator of the proportion of female commissioners as an independent variable, company performance as a dependent variable using an indicator of return on assets. Descriptive analysis techniques, correlation coefficient and determination coefficient tests were carried out to analyze the data. The results show that corporate governance has a significant effect on company performance. It was also found that women on board had a significant effect on the firm performance of a cosmetic company listed on the Indonesia Stock Exchange in 2015-2019.
\end{abstract}

\section{Pendahuluan}

Meningkatnya pengguna produk kosmetik dikalangan kaum wanita untuk mempercantik diri dengan merias diri dan merawat tubuh, mendorong peralihan tingkatan pengguna kosmetik dari level pelengkap menjadi sebuah kebutuhan, sehingga dapat mendorong pertumbuhan industri kosmetik. Namun, seiring dengan perkembangan zaman, kosmetik menjadi kebutuhan yang bukan hanya digunakan untuk para kaum wanita saja, maka hal ini memberikan peluang bagi industri kosmetik di Indonesia, sehingga banyak bermunculan merek baru dipasaran yang dapat menimbulkan persaingan cukup ketat.

Dalam suatu perusahaan dibutuhkan pengelolahan dan strategi perusahaan yang baik dan benar agar dapat tercapainya suatu tujuan. Dan setiap perusahaan akan melakukan kinerja yang terbaik untuk tercapainya tujuan suatu organisasi maupun perusahaan. Kinerja keuangan perusahaan dapat diukur dengan menggunakan rasio profitabilitas. Return on assets digunakan sebagai salah satu indikator yang digunakan peneliti untuk menilai seberapa efisien perusahaan menggunakan aset yang dimiliki untuk memaksimalkan laba. Karena zaman sekarang banyak perusahaan bersaing untuk meningkatkan keuangan 
perusahan tersebut. Karena banyak para investor menilai perusahaan dari laporan keuangan perusahaan tersebut. Maka dari itu bisa di bilang corporate governance (GC) adalah suatu bagian terpenting dalam perusahaan untuk dapat mengelola perusahaan dengan baik dengan mengatur hubungan antara dewan komisaris, pemegang saham dan pengurus lainnya.

Walaupun saat ini perkembangan dunia bisnis semakin erat persaingannya, dan seluruh perusahaan berlomba untuk tetap memaksimalkan laba dari semua hasil kinerja perusahaan agar dapat mempertahankan kelangsungan bisnis, tetapi tetap bisa mengatur risiko dengan baik dan benar. Dalam pengelolahan suatu perusahaan, Corporate Governance bisa dikatakan menjadi suatu penyambung antara pihak manajemen dan pihak pemegang saham agar dapat mengatur dan mengendalikan suatu pengelolaan bisnis termasuk juga di dalamnya pengelolaan risiko. Semua bagian corporate governance juga bisa memberikan sarana untuk menentukan teknik. Suatu perusahaan untuk dapat memilih teknik pengaturan suatu perusahaan maka sangat di perlukan peran Corporate Governance untuk dapat melengkapi semua ketetapan sasaran dari perusahaan tersebut (Darmawati, 2005).

Demikian juga hal ini sesuai dengan kasus yang terdapat pada situs berita Kontan.co.id oleh Tendi Mahadi (2019) yaitu direktur utama bank BJB Yuddy Renaldi yang menyatakan bahwa beliau meyakini kasus korupsi bisa dicegah dengan cara menetapkan kebiasaan GCG secara berkesinambungan. Dikatakan juga bahwa bagian GCG ini bisa membuat pedoman tatakelola perusahaan yang baik dan benar. Dan dengan demikian Bank BJB melakukan penerapan GCG atau good corporate governance adalah merupakan sebuah keharusan untuk menaikkan prestasi perusahaan.

Hal ini sesuai dengan berita yang terdapat pada situs berita Kontan oleh Syafina (2014) yang mengatakan bahwa OJK menekankan pentingnya peran komisaris dalam tata kelola perusahaan dengan memberikan 14 point peran tersebut. Kepala Eksekutif Pengawas Pasar Modal OJK Nurhaida menggungkapkan, nantinya ada sekitar 14 poin yang akan menjadi tanggungjawab dewan komisaris dan direksi emiten terhadap perusahaannya. Diharapkan dengan peraturan ini komisaris independen juga tidak diperbolehkan merangkap jabatan menjadi direktur perusahaan lain karna waktunya akan terganggu. Dengan demikian OJK mengharapkan agar tatakelola perusahaan bisa dilaksanakan dengan baik sehingga suatu perusahaan dapat berkinerja dengan baik pula.

Women on board of commissioner (WOMC) adalah dimana di temukan banyaknya proporsi perempuan yang menjabat sebagai dewan komisaris. Siagian (2018), dalam penelitiannya menyatakan terdapat pengaruh proporsi komisaris wanita terhadap kinerja perusahaan. Suatu perusahaan akan berusaha meningkatkan performa kinerjanya untuk mendapatkan suatu kepercayaan dari para investor. Dalam merencanakan suatu kegiatan perusahaan sangat membutuhkan corporate governance (Ariyoto, 2000:10). Implementasi corporate governance yang terbaik yang sesuai dengan suatu anggaran yang aktif bisa melancarkan niat investor yang merespon dengan baik kepada prestasi perusahaan dan dapat meningkatkan kinerja perusahaan.

Corporate governance adalah kunci sukses untuk mengelola suatu perusahaan sehingga semua laporan keuangan yang dapat dihasilkan terjamin kualitasnya (Velnampy, 2013) Corporate governance adalah suatu konsep yang bisa digunakan untuk meningkatkan suatu sistem ekonomi, yang memiliki hubungan antara para pemegang saham, dewan direksi, manajemen perusahaan, dan pemangku kepentingan lainnya (Gitman dan Zutter, 2012). Konsep dari corporate governance diadakan demi tercapainya pengelolaan suatu perusahaan yang lebih terbuka bagi seluruh pengguna laporan. Bila konsep tersebut dapat diterapkan dengan baik maka diharapkan pertumbuhan ekonomi akan meningkat sejalan dengan 
kejelasan pengelolaan perusahaan yang semakin baik dan akan menguntungkan banyak pihak. Dengan demikian peneliti ingin menguji pengaruh antara corporate governance dan woman on board terhadap kinerja perusahaan kosmetik.

\section{Kajian Teori dan Telaah Literatur}

\section{Kinerja Perusahaan}

Kinerja perusahaan diartikan sebagai kemampuan perusahaan untuk mencapai tujuannya melalui pemakaian sumber daya secara efisien dan efektif dan menggambarkan seberapa jauh suatu perusahaan mencapai hasilnya setelah dibandingkan dengan kinerja terdahulu previous perfomance dan kinerja organisasi lain benchmarking, serta sampai seberapa jauh meraih tujuan dan target yang telah ditetapkan (Nugrahayu dan Retnani, 2015).

Kinerja perusahaan adalah hal yang dapat diperoleh oleh organisasi/perusahaan tersebut dalam jangka waktu yang di tentukan. Menurut Mulyadi (2001) perusahaan yang memiliki kemampuan yang baik tentu akan berkelanjutan, dikarenakan para investor memiliki keyakinan bahwa ketika berinvestasi di perusahaan tersebut maka akan menghasilkan laba pada modal yang telah ditanamkan.

Pertumbuhan dunia bisnis saat ini yang erat persaingannya, menyebabkan semua industry berjuang sebaik mungkin untuk mengintensifkan pendapatan pada pengoperasianya, untuk meningkatkan kesinambungan bisnis tersebut, tetapi memperhatikan pengaturan pada risiko-risiko yang ada. (Syafiqurrahman, 2014.) Laporan keuangan yang berhubungan pada kinerja dapat digunakan sebagai fondasi untuk mengetahui hasil kinerja dari perusahaan, karena untuk mengetahui suatu perusahaan berhasil atau tidaknya pada setiap periode dapat diketahui dengan menggunakan pengukuran pada laporan keuangan. Kinerja keuangan dalam penelitian ini menggunakan ROA.

\section{Corporate Governance}

Dalam suatu perusahaan akan ada keseimbangan apabila anggotanya berasal dari berbagai macam latar belakang yang membantu pekerjaan suatu perusahaan (diversifikasi) yang dapat dikerjakan lebih efektif dan efisien (Abdullah, 2016). Di dalam dewan suatu perusahaan akan ada salah satu masalah mengenai diversifikasi. Salah satu masalah mengenai diversifikasi dewan adalah proporsi jenis kelamin di dalam dewan perusahaa (Syamsudin et al, 2017).

Women on board of commissioner (WOMC) adalah dimana di temukan banyaknya proporsi perempuan yang menjabat sebagai dewan komisaris (Syamsudin et al, 2017). Women on board of director (WOMD) adalah dimana ditemukan banyaknya proporsi perempuan di dalam dewan direksi (Syamsudin et al, 2017). Keberadaan perempuan dapat dipandang sebagai sarana untuk meningkatkan tatakelola perusahaan di samping menambah diversitas dewan korporasi, yang mana dewan didominasi oleh laki-laki ("old-boy" networks)

Dengan adanya dewan komisaris perempuan didalam jajaran dewan perusahaan dianggap bisa meninggikan kinerja perusahaan karena pada dasarnya jika adanya wanita diperusahaan berarti bisa memberikan harapan kepada siapa saja, tanpa pembedaan untuk menjadi bagian dari dewan perusahaan. 
Setiap perusahaan bisa dikatakan mempunyai kualitas yang bagus apabila dilihat dari kapasitas keuangannya. Dalam mencapai laba perusahaan kapasitas keuangan tersebut dapat dijadikan standar kesuksesan bagian manajemen. (Darmawati, et al 2005). Penerapan kegiatan corporate governance yang baik, sangat perlu ditegakkan dalam pencapaian kinerja perekonomian suatu perusahaan yang maksimal. Corporate governance yang diwakili sebagai para manajer yaitu dewan komisaris dan direksi yang harus di kelola hubungannya agar tidak terjadi konflik dengan semua para pemegang saham.

Penelitian yang dilakukan oleh (Hidayah, 2008) menyatakan tidak ada pengaruh corporate governance dengan prestasi perusahaan-perusahaan manufaktur yang terdaftar di Bursa Efek Indonesia (BEI). Namun banyak penelitian yang dilakukan sebelumnya mengenai pengaruh corporate governance dan woman on board menyatakan pentingnya hubungan antara corporate governance dengan prestasi perusahaan yang Gompers, et al (2003) perusahaan manufaktur yang terdaftar di Bursa Efek Indonesia (BEI) periode 2007-2009. Alisa Jihan Siffiana, et al (2020) pada perusahaan gudang garam. Darmawati, et al (2004) perusahaan yang terdaftar di Bursa Efek Indonesia/Indonesia Stock Exchange, selama periode 2010, Klapper\& love (2003) perusahaan manufaktur yang terdaftar di BEI periode 2010- 2012, Black, et al (2013) perusahaan pada sektor keuangan, Mitton (2002) perusahaan hasil survei The Indonesian Institute of Corporate Governance (IICG) dan Febriyana (2007) perusahaan publik yang terdaftar di BEI.

$\mathbf{H}_{1}$ : Corporate Governance mempengaruhi Kinerja Perusahaan.

\section{Women on Board}

Dengan adanya perempuan di dalam dewan komisaris yang dimana kita tahu bahwa wanita cenderung mempunyai sifat yang lebih hati-hati, lebih teliti sehingga dapat menghindari dan dapat menangani setiap resiko dengan lemah lembut dan hati-hati di bandingkan dengan laki-laki (Syamsudin et al, 2017). Kehadiran anggota direksi perempuan akan lebih membantu perusahaan untuk meningkatkan kinerja perusahaan (Siagian, 2018).

Penelitian-penelitian yang dilakukan sebelumnya oleh Erhardt et al. (2003), Mc Kinsey (2010), Teg Teg dan Utami (2013) dan Adnan, et al (2013) menyatakan adanya pengaruh signifikanan atara women on board dengan kinerja perusahaan. Sedangkan pelitian sebelumnya dilakukan oleh Adams dan Ferreira (2009) menyatakan tidak ada pengaruh penting antara women on board dengan prestasi suatu perusahaan.

$\mathbf{H}_{2}$ : Women on Board of Commisioner mempengaruhi Kinerja Perusahaan.

\section{Metode Penelitian}

Dalam penelitian ini penulis menggunakan metode deskriptif dengan data sekunder. Penelitian ini mengkaji beberapa perusahaan kosmetik yang tercatat di BEI diperiode 20152019. Penelitian ini mengkaji seluruh 30 perusahaan kosmetik yang memiliki data dari tahun observasi 2015-2019, maka penelitian ini menggunakan keenam perusahaan tersebut sebagai sampel penelitian.

Menurut (Sugiyono, 2012) metode deskriptif adalah statistik yang bertujuan untuk mendeskripsikan atau memberikan gambaran tentang objek yang diteliti melalui data atau 
sampel yang dikumpulkan tanpa melakukan analisis dan membuat kesimpulan yang diterima secara umum. Pada kasus ini, Metode deskriptif yang digunakan bertujuan untuk memprediksi sejauh mana pengaruh yang akan ditimbulkan variabel independen yaitu Corporate Governance (X1) dan Women On Board (X2) terhadap dependen variabel yaitu Kinerja Perusahaan $(\mathrm{Y})$.

Menurut (Sugiyono, 2012) data sekunder adalah data diperoleh melalui membaca, mempelajari, dan memahami buku, dokumen, dan literatur. Sumber data sekunder ini diperoleh dari Bursa Efek Indonesia, penelitian ini menggunakan informasi keuangan dari 30 perusahaan kosmetik, dengan 6 kode perusahaan ADES, MBTO, MRAT, TCID, KINO, UNVR. Penelitian ini juga untuk melihat bagaimana prospek perusahaan-perusahaan kosmetik sebelum adanya pandemik Covid-19 maka dari itu sumber data penelitian ini diambil dari laporan keuangan pada tahun 2015-2019.

\section{Hasil dan Pembahasan}

Uji-t

Tabel 1. Hasil Analisis Regresi

\begin{tabular}{llcccc}
\hline Model & $\begin{array}{l}\text { Unstandardized } \\
\text { coefficients }\end{array}$ & & \multicolumn{3}{c}{$\begin{array}{l}\text { Standardized } \\
\text { Coefficients }\end{array}$} \\
& $\mathbf{B}$ & Std. & Beta & $\mathbf{t}$ & Sig \\
\hline 1(constant) & 1.456 & Error & & .270 & .789 \\
CG & 21.059 & 5.399 & & .641 & .014 \\
WOM & -20.921 & 7.975 & .421 & -2.121 & .043 \\
\hline
\end{tabular}

a.DV: ROA

Sumber: Data yang diolah, 2021

Pada tabel di atas menunjukkan hasil nilai dari koefisien CG sebanyak 21.059 dengan t-CG $=$ 7.975 dan dengan signifikansi $\mathrm{p}<5 \%$ (sig. 0.014). Dan dari hasil di atas menyatakan bahwa secara signifikan variabel tata kelola perusahaan mempengaruhi variabel kinerja perusahaan.

Dalam pengkajian ini menyatakan bahwa hipotesa 2 terdapat pengaruh yang signifikan yaitu women on board dan kinerja perusahaan. Dan begitu juga hasil pengkajian menunjukkan bahwa adanya pengaruh yang penting antara women on board dan kinerja perusahaan pada perusahaan kosmetik dari tahun 2015-2019 dengan nilai t-WOM -2.121 dan $\mathrm{p}<5 \%$ (sig. 0.043). Hasil regresi dari penelitian ini dapat dilihat sebagai berikut:

$\mathrm{ROA}=1.456+21.059 \mathrm{CG}-20.921 \mathrm{WOM}$.

Hasil pengkajian ini didukung oleh penelitian terdahulu yang mengatakan bahwa untuk hipotesis 1, bahwa ada pengaruh yang signifikan antara corporate governance dan kinerja perusahaan seperti yang ditulis oleh Prasetyo (2014) dan Gompers, et al (2003). Dengan demikian benar bahwa tata kelola yang baik yang diperankan oleh komisaris independen dapat turut membantu menaikkan kinerja perusahaan.

Terkait hipotesis kedua 2, hasil penelitian mendukung hipotesa tersebut dengan mendapati bahwa ada pengaruh yang signifikan antara women on board dan kinerja perusahaan seperti yang ditulis oleh Setiani (2010), Puspaningsih (2013), Fenandar (2012), Dahlan (2016) dan Siagian (2018). Meskipun ada beberapa peneliti yang memiliki hasil sebaliknya yaitu Ghosh, et al (2014), dan Hernandes (2015). Dengan demikian benar bahwa tata kelola yang baik 
yang diperankan oleh komisaris wanita dapat turut membantu menaikkan kinerja perusahaan.

\section{Penutup dan Saran}

Berdasarkan hasil dari pengkajian statistik dan pengujian untuk mendapat bukti yaitu adanya pengaruh signifikan antara corporate governance dan kinerja perusahaan. Kinerja keuangan suatu perusahaan akan tetap stabil atau bahkan dapat meningkat jika diterapkannya corporate governance secara baik dan benar. Dalam merencanakan suatu kegiatan perusahaan sangat membutuhkan corporate governance. Didapati pula adanya pengaruh signifikan women on board dan kinerja perusahaan. Dan untuk analisa pengaruh woman on board sebagai variabel independen ternyata ada hubungan signifikan dalam meningkatkan kinerja perusahaan. Dan untuk mempengaruhi kinerja perusahaan yaitu sebagai variabel dependen yaitu meningkatnya laporan keuangan suatu perusahaan sangat perlunya dewan direksi bekerja dengan baik untuk selalu memperhatikan kinerja manajemen agar laporan keuangan suatu perusahaan tersebut tetap stabil atau bahkan meningkat. Hasil dari penelitian secara simultan juga mendapati bahwa corporate governance dan women on board ternyata kedua variabel tersebut sangat berpengaruh terhadap kinerja perusahaan sub sektor kosmetik tahun 2015-2019.

\section{Saran}

Adapun saran yang dapat penulis berikan dari hasil penelitian ini yaitu: setiap perusahan harus selalu melakukan kinerjanya dengan baik dan benar. Dan setiap perusahaan harus menerapkan CG atau Corporate Governance dengan baik agar manajemen perusahan tetap stabil dan bahkan dapat meningkat. Baik pimpinan perempuan maupun laki-laki pada saat memimpin seharusnya atau bahkan disarankan untuk tetap melakukan GCG dengan baik dan benar agar setiap tujuan suatu perusahaan dapat terlaksana dengan baik. Untuk penelitian selanjutnya dapat melakukan pengkajian lebih dalam mengenai women on board of commisioner yang mempengaruhi bagian lainnya pada perusahaan.

\section{Referensi}

Abdullah, S. N. (2014). The causes of gender diversity in Malaysian large firms. Journal of Management \& Governance, 18(4), 1137-1159.

Abdullah, S. N., Ismail, K. N. I. K., \& Nachum, L. (2016). Does having women on boards create value? The impact of societal perceptions and corporate governance in emerging markets. Strategic Management Journal, 37(3), 466-476.

Adams, R. B., \& Ferreira, D. (2009). Women in the boardroom and their impact on governance and performance. Journal of financial economics, 94(2), 291-309.

Ariyoto, K. (2000). Good corporate governance dan konsep penegakannya di BUMN dan lingkungan usahanya. Jurnal Usahawan, (10), 3-17.

Black, B. S., Kim, W., Jang, H., \& Park, K. S. (2005). How corporate governance affects firm value: Evidence on channels from Korea. School Of Law Law And Econ Research Paper, (09-23). 
Carter, D. A., D'Souza, F., Simkins, B. J., \& Simpson, W. G. (2010). The gender and ethnic diversity of US boards and board committees and firm financial performance. Corporate Governance: An International Review, 18(5), 396-414.

Carter, D. A., Simkins, B. J., \& Simpson, W. G. (2003). Corporate governance, board diversity, and firm value. Financial review, 38(1), 33-53.

Darmawati, D., Khomsiyah, K., \& Rahayu, R. G. (2005). Hubungan Corporate Governance dan kinerja perusahaan. The Indonesian Journal of Accounting Research, 8(1).

Erhardt, N. L., Werbel, J. D., \& Shrader, C. B. (2003). Board of director diversity and firm financial performance. Corporate governance: An international review, 11(2), 102-111.

Gitman, L. J., Juchau, R., \& Flanagan, J. (2015). Principles of managerial finance. Pearson Higher Education AU.

Gompers, P., Ishii, J., \& Metrick, A. (2003). Corporate governance and equity prices. The quarterly journal of economics, 118(1), 107-156.

Healy, P. M. (1985). The effect of bonus schemes on accounting decisions. Journal of accounting and economics, 7(1-3), 85-107.

Healy, P. M. (1985). The effect of bonus schemes on accounting decisions. Journal of accounting and economics, 7(1-3), 85-107.

Ismail, K., Abdullah, S. N., \& Nachum, L. (2013). Women on boards of directors of Malaysia firms: Impact on market and accounting performance. Academy of Management Global Proceedings, (2012), aomafr-2012.

Klapper, L. F., \& Love, I. (2004). Corporate governance, investor protection, and performance in emerging markets. Journal of corporate Finance, 10(5), 703-728.

Mitton, T. (2002). A cross-firm analysis of the impact of corporate governance on the East Asian financial crisis. Journal of financial economics, 64(2), 215-241.

Mulyadi, B. S. (2001). Alat Manajemen Kontemporer Untuk Pelipatgandaan Kinerja Keuangan Perusahaan. Jakarta: Salemba Empat.

Nugrahayu, E. R., \& Retnani, E. D. (2015). Penerapan Metode Balanced Scorecard Sebagai Tolok Ukur Pengukuran Kinerja Perusahaan. Jurnal Ilmu dan Riset Akuntansi (JIRA), 4(10).

Siagian, V. (2018). Women on Board and Firm Performance: Evidence From Indonesia LQ45. Jurnal Terapan Ilmu Manajemen dan Bisnis (JTIMB), 1(1), 98-110.

Siffiana, A. J., Septiana, W., \& Hana, K. F. (2020). Pengaruh Corporate Governance Terhadap Kinerja Perusahaan Gudang Garam. Point, 2(1).

Syafirqurrahman, M., Andiarsyah, W., \& Suciningsih, W. (2014). Analisis pengaruh corporate governance dan pengaruh keputusan pendanaan terhadap kinerja perusahaan perbankan di indonesia. Jurnal Akuntansi, 18(1), 21-44.

Syamsudin, S., Setiany, E., \& Sajidah, S. (2017). Gender diversity and firm value: a study on boards of public manufacturing firms in Indonesia. Problems and perspectives in management, (15, Iss. 3 (contin. 1)), 276-284. 
Terjesen, S., Couto, E. B., \& Francisco, P. M. (2016). Does the presence of independent and female directors impact firm performance? A multi-country study of board diversity. Journal of Management \& Governance, 20(3), 447-483.

Wijaya, B. I., \& Sedana, I. P. (2015). Pengaruh profitabilitas terhadap nilai perusahaan (kebijakan dividen dan kesempatan investasi sebagai variabel mediasi). E-Jurnal Manajemen, 4(12). 